\title{
LA CONVERSIÓN DE 1846 DE LA DEUDA \\ INGLESA Y LA GUERRA DE INTERVENCIÓN ESTADOUNIDENSE \\ Alfonso Carballo*
}

$\mathrm{E}_{128 \text { de noviembre de } 1846, \text { el mi- }}$ nistro español en México, Salvador Bermúdez de Castro, informaba a su gobierno sobre un escándalo ocurrido con una negociación de la deuda externa mexicana efectuada en Londres el 4 de junio de ese mismo año. ${ }^{1}$ En efecto, el escándalo había llegado a tal magnitud que dos importantes cabezas habían rodado: el ministro mexicano en Londres, Tomás Murphy, quien llevó a efecto la negociación en aquella ciudad, había sido removido de su cargo el 28 de agosto de 1846 por el ministro de Hacienda, Valentín Gómez Farías, quien aprovechó la

* Licenciado en Economía por el Instituto Tecnológico Autónomo de México y asesor de la Unidad de Desregulación Económica de la SECOFI. Quiero agradecer a Raúl Figueroa Esquer por haberme proporcionado las transcripciones de la correspondencia diplomática de Salvador Bermúdez de Castro, que cito en este artículo. Asimismo, agradezco a mi asistente, José Raúl Castilleja Montiel, por su valiosa ayuda para la presente investigación.

${ }^{1}$ Desp. 394 de Salvador Bermúdez de Castro al Primer Secretario del Despacho de Estado (de ahora en adelante P.S.D.E.), México, 28 de noviembre de 1846, AMAE, Leg. 1649. 


\section{ALFONSO CARBALLO}

ocasión para desconocer la negociación. Por otra parte, el 29 de octubre de ese mismo año, un nuevo ministro de Hacienda, Antonio Haro y Tamariz, reconoció la negociación llevada a cabo por Murphy y pidió que se pagaran los dividendos correspondientes al próximo mes de enero; esto causó múltiples ataques e imputaciones por parte de la prensa hacia Haro, pues se decía que la negociación era contraria a los intereses de la nación, lo que provocó la remoción de su cargo. Ante esto, los tenedores de bonos estaban molestos, pues ya se habían realizado tres intentos - entre 1845 y 1846 - de renegociación de la deuda, y el pago de los dividendos no se había efectuado desde octubre de 1844. La desconfianza de los tenedores se agudizaba con el arribo de Mariano Salas al poder, vaticinando el regreso de Santa Anna, bajo cuya última presidencia, especialmente en el año 1842, se cometieron grandes fraudes en las negociaciones referentes al manejo de la deuda.

El gobierno mexicano contrató dos préstamos en la Bolsa de Londres en 1824 y $1825 .^{2}$ Después de una serie de interrupciones en el pago de los intereses y de varios intentos por restablecerlos, en el año 1837, el gobierno mexicano realizó un nuevo arreglo con el cual intentaba poner solución a dos problemas a los que se enfrentaba: el arreglo de su deuda externa y la independencia de Texas. Las autoridades pensaban que el involucrar intereses de otras potencias en la cuestión de Texas serviría de contrapeso ante la agresión de los Estados Unidos; por lo que intentaron hacer una amortización forzosa de la mitad de la deuda dando a cambio a los tenedores británicos escrituras de terrenos baldíos en el Norte del país, iniciativa que fracasó ante su oposición. Sin embargo, la conversión de 1837 juntó el monto de los dos préstamos externos en un solo fondo; éste se dividiría en la

${ }^{2}$ La deuda contratada tuvo los siguientes montos: en 1824, £3,200,000 de la casa B.A. Goldschmidt y Compañía al $5 \%$ de interés anual y con un período de amortización de 30 años; en $1825, £ 3,200,000$ de la casa Barclay, Herring, Richardson y Compañía al $6 \%$ de interés anual y con un período de amortización de 30 años. 
mitad, creando así dos tipos de bonos: activos, por la mitad del fondo, lo cuales pagarian intereses de $5 \%$ anual; por la otra mitad de la suma se entregarían bonos diferidos que no generarían dividendos hasta octubre de $1847 .^{3}$ Además, se dejó la posibilidad de que los tenedores de bonos d:feridos pudieran canjear sus títulos, si así lo deseaban, por terrenos baldíos en el Norte del país. La aprobación de este convenio por parte del Congreso demoró tanto que, junto con la primera guerra contra Francia, impidieron nuevamente que México restableciera el pago de intereses. ${ }^{4}$ Por lo anterior, los tenedores solicitaron que se efectuara una capitalización de los intereses atrasados ${ }^{5}$ mediante un acuerdo celebrado entre la agencia de México en Londres, la casa Lizardi, y el Comité de Tenedores de Bonos Hispanoamericanos en febrero de 1842, con el cual se expidieron nuevos títulos llamados debenturas por 499,096 libras. $^{6}$

A principios de la década de 1840 , bajo la administración santannista se cometieron grandes fraudes contra el crédito mexicano debido a diversas emisiones clandestinas de bonos de la deuda que Lizardi efectuó, con la autorización del gobierno, para cobrar sus comisiones. En 1837, Agustín de Iturbide hijo, quien fungía como encargado de ne-

${ }^{3}$ La suma de bonos activos después de la conversión de 1837 debería de ser de $£ 4,623,689$ y una cantidad similar por los bonos diferidos. Empero, como más adelante mencionaré, se mandaron a imprimir bonos por la cantidad de $£ 5,500,000$, lo cual representaba una sobre emisión que afectaría durante muchos años la reputación del crédito mexicano.

${ }^{4}$ Joaquín Casasús, Historia de la deuda contraida en Londres, 1885 , México, Imp. del Gobierno en Palacio, p. 143-59.

${ }^{5}$ Lucas Alamán, Liquidación general de la deuda esterior de la República Mexicana hasta fin de diciembre de 1841, 1845, México, Imp. Ignacio Cumplido, p. 393.

${ }^{6}$ Convenio de 10 de febrero de 1842 , entre tenedores de bonos y la Casa de Lizardi, apud, Congreso, seyes, Decretos y Convenios relativos a la deuda estrangera, que se reunen para la fácil inteligencia del dictamen de la Comisión de Crédito Público de la cámara de diputados, [1850], México, [s.i] p. XXXIII-XXXVI. 


\section{ALFONSO CARBALLO}

gocios de México en Londres, firmó por la suma de 5,500,000 libras en bonos activos y una misma cantidad de diferidos, en lugar de 4,623,689 respectivamente, dando lugar a una sobre emisión. Por la conversión de 1837 , el gobierno otorgó a Lizardi como pago a sus gestiones el $2 \frac{1}{2} \%$ del monto de la conversión y por la pequeña capitalización de las debenturas le concedió 200,000 libras. Para cobrarse, Lizardi emitió el sobrante de los bonos activos, que no estaban autorizados, incrementando el monto de la deuda activa a 5,500,000 libras en lugar de 4,623,689 que establecía la conversión de $1837 .^{7}$ Posteriormente, con el propósito de pagar los intereses de la deuda, Lizardi activó una cantidad de bonos diferidos por 91,650 libras que pertenecían a la sobre emisión de 1837 . En diciembre de 1843, Valentín Canalizo, como presidente interino, reconoció todas las elevadas comisiones de la casa Lizardi, por lo que la deuda se incrementó a la descomunal cifra de 10,714,742 libras. ${ }^{8}$ Lizardi aún mantenía en su poder la suma de 784,350 libras de bonos diferidos que eran producto de una emisión clandestina. ${ }^{9}$

${ }^{7}$ De acuerdo con el decreto emitido en diciembre de 1843 por el presidente interino, Valentín Canalizo, la cantidad de $£ 4,623,689$ por la deuda de los bonos activos y otra igual cantidad por los bonos diferidos, fueron incrementadas a $£ 4,624,000$, redondenado así la cantidad adeudada en perjuicio de la nación. Por esta razón, la suma que Lizardi cobró efectivamente por la comisión del $2 \frac{1}{2} \%$ fue de $£ 876,000$.

${ }^{8}$ La suma se desagrega de la siguiente manera:

Bonos activos reconocidos por Canalizo $4,624,000$

Comisión a Lizardi de $2 \frac{1}{2} \%$ en bonos activos 876,000

Bonos diferidos que se activaron para el pago de intereses. 91,650

Monto de las debenturas 499,096

Monto de los bonos diferidos reconocidos por Canalizo $4,624,000$

Total $10,714,746$

${ }^{9}$ Según Salvador Bermúdez de Castro, un agente de Lizardi se trasladó a Manga de Clavo, hacienda de Santa Anna, para acordar la suma con la que se compraría la aprobación. Desp. 32, de Salvador Bermúdez de Castro al P.S.D.E., México, 27 de abril de 1845, AMAE, Leg. 1648. 
La conversión de 1846 data desde principios de 1845, bajo la presidencia de José Joaquín Herrera. El 28 de febrero de ese año el Congreso norteamericano había decretado la anexión de Texas. Esto se traducía en una amenaza para México, por lo que el gobierno intentó poner orden en sus finanzas públicas para enfrentar la nueva situación. El arreglo de la deuda externa era necesario para lograr tal fin, pues debido a los escándalos que se cometieron bajo la administración santannista, resultaba imposible que el gobierno pudiera hacerse de nuevos recursos en el exterior sin recomponer el deteriorado prestigio de México en los mercados financieros internacionales. De hecho, primeramente se planteó la posibilidad de contratar un préstamo de tres millones, pero la Comisión Primera de Hacienda y el ejecutivo concluyeron que sería impracticable si no se arreglaba primero el crédito exterior. Para esto, se removió inmediatamente a Lizardi como agente del gobierno en Londres el 5 de marzo, dejando en su lugar a la casa Schneider. ${ }^{10}$ Lizardi se negó a entregar la documentación y 65,651 libras que mantenía en su poder, destinadas al pago de los dividendos. Los tenedores demandaron a Lizardi ante un tribunal británico, por lo que finalmente entregó el dinero y la documentación a la casa Schneider. Sin embargo, Lizardi aún poseía los bonos clandestinos por la suma de 784,350 libras. " Aunque estos bonos no estuvieran en circulación, el simple hecho de su existencia y la posibilidad de que Lizardi los expidiera, provocaba que el precio de los bonos activos en el mercado se viese afectado.

En total, existían diferentes tipos de bonos: activos por 5,591,650 libras, que generaban intereses; diferidos, por 4,624,000 libras, que

${ }^{10}$ En un primer momento, bajo la presidencia de Herrera, el Ministerio de Hacienda fue ocupado por Pedro Echeverría quien no removió a Lizardi de la agencia. Según el ministro de España en México, Salvador Bermúdez de Castro, se debía a que Echeverría tenía nexos familiares con Manuel Lizardi; por esta razón Echeverría fue sustituido por Mariano Riva Palacio, ibid.

${ }^{11}$ Congreso, Dictamen de la Comisión de Crédito Público de la Cámara de Diputados, sobre el arreglo de la Deuda Inglesá, 1850, México, Imp. Ignacio Cumplido, p. 17. 


\section{ALFONSO CARBALLO}

se activarían en octubre de 1847; debenturas, por 499,096 libras; y clandestinos por 784,350 libras, que de llevarse una nueva conversión, estos últimos quedarian sin validez.

\section{Distribución de bonos mexicanos según su tipo}

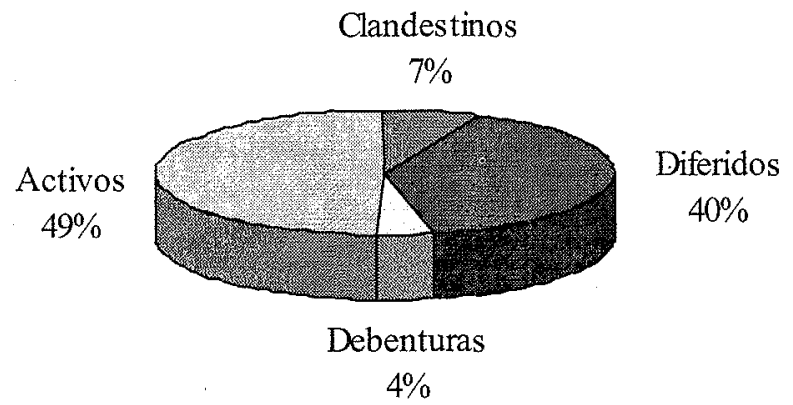

32 Es así como el ministro de Hacienda, Luis de la Rosa, presentó ante el Congreso una iniciativa de ley para arreglar la deuda externa e interna el 19 de abril de 1845. Las bases para realizar la negociación radicaron en cuatro puntos: que los intereses atrasados no se capitalizaran; que el interés del 5\% no se incrementara; tampoco el capital de la deuda; y que no se hipotecara el territorio nacional en el arreglo. ${ }^{12}$ El 22 de abril la Primera Comisión de Hacienda de la Cámara de Diputados emitió su dictamen respecto a la iniciativa del día 19, donde expresaba que estaba de acuerdo con la propuesta y que era urgente que se llevara a efecto lo más pronto posible, ante la amenaza producida por la agregación de Texas a los Estados Unidos. Indicaba que en esta negociación no deberían capitalizarse los intereses atrasados, puesto que de ser así el monto de la deuda se incrementaría. Esto sería

${ }^{12}$ Diario del Gobierno, México, 19 de abril de 1845. 
un grave error con el cual la conversión de la deuda tropezaría con la inconformidad de los tenedores. ${ }^{13}$

El 28 de abril de 1845, apegándose a la iniciativa de Luis de la Rosa, el Congreso expidió un decreto para que el ejecutivo arreglara el crédito exterior. ${ }^{14}$ Con lo anterior, se hace el primer intento por negociar la deuda externa, de tres que fracasarían por llevar a cabo la conversión que culminaría en 1846. Al día siguiente, una de las poderosas casas financieras en México, Manning y Mackintosh, ofrecía al gobierno un plan muy atractivo para llevar a cabo la negociación. El plan consistía en crear un fondo nacional consolidado por el valor de 4,000,000 libras para sustituir los bonos diferidos y debenturas. Es decir, después de la negociación el gobierno iba a tener una deuda de 4,000,000 en lugar de las 5,123,096 libras que anteriormente adeudaba, correspondientes a los bonos diferidos y debenturas. La tasa de interés sería del $5 \%$ anual a ochenta años, desde enero de 1846 hasta enero de 1926; también se destinarían 250,000 pesos anuales para la amortización del fondo. El gobierno se comprometía ante los tenedores de bonos a destinar para el pago de los intereses y amortizaciones de este nuevo fondo la cantidad de 83,333 pesos mensuales, provenientes de una de sus mejores fuentes de ingreso: la renta del tabaco. Manning y Mackintosh canjearía los viejos bonos de los tenedores por nuevos y, de acuerdo al precio del mercado, se quedaría con el sobrante de las 4,000,000 libras del fondo. A cambio de esto, la casa estaba obligada a proporcionar al gobierno la cantidad de 5,000,000 de pesos en bonos del $26 \%$ de la deuda interior y dos millones de pesos en numerario. La casa debía entregar el 31 de agosto de 1846 los cinco millones de pesos en bonos del $26 \%$, mientras que los dos millones de pesos en

${ }^{13}$ Congreso, Dictamen de la Primera Comisión de Hacienda de la Cámara de Diputados sobre que se autorice al gobierno arreglar la deuda esterior, México, 22 de abril de 1845.

${ }^{14}$ Ley de 28 de abril de 1845 , sobre arreglo de la deuda esterior que dio origen a la conversión de 1846 y demás documentos oficiales relativos a la misma conversión de 1846, apud, Congreso, Leyes..., op. cit., p. XXX-XXXVII. 


\section{ALFONSO CARBALLO}

numerario se entregarían de la siguiente forma: 250,000 pesos el 8 de mayo; 250,000 el $1^{\circ}$ de junio; y el resto en abonos de 300,000 pesos mensuales a partir del 20 de octubre de 1845. La casa informaría el 20 de septiembre de 1845 si ratificaba el convenio; en caso de no ser así, el gobierno devolvería los 500,000 pesos que le habían entregado en mayo y junio. ${ }^{15}$ La negociación era buena puesto que además de arreglar el problema de su crédito exterior, el gobierno lograba una reducción en su deuda interna de 5,000,000 de pesos provenientes del fondo del 26\%; el monto de la deuda exterior por concepto de los bonos diferidos y debenturas disminuía de 5,123,096 a 4,000,000 libras, y se hacía de 2,000,000 de pesos en efectivo.

El secretario de Hacienda informó a Tomás Murphy y la casa Schneider sobre los acuerdos celebrados el día 29 de abril. ${ }^{16}$ Guillermo O'Brien, comerciante con residencia en París, fue enviado ex profeso por el gobierno para realizar la conversión. ${ }^{17}$ Las noticias llegaron a Londres a mediados de junio de 1845 , pero Schneider informó a Murphy que el convenio era impracticable, pues los tenedores de bonos no tenían ninguna obligación de entregar sus títulos. Además, sería imposible que con los 4,000,000 de libras del fondo fuera suficiente para realizar la compra de todos los bonos diferidos y debenturas. ${ }^{18}$ Schneider recomendaba que el gobierno hiciera algunas modificaciones al contrato con Manning y Mackintosh. Los tenedores aceptarían la conversión, siempre que les presentaran una oferta atractiva y que no demorara más tiempo, pues se acercaba la fecha en que los bonos diferidos causarían interés, lo que complicaría la operación. Schneider preguntó a Murphy si como ministro tenía facultades para modificar

${ }^{15}$ Ibid.

${ }^{16}$ Desp. 1 de Luis de la Rosa a Tomás Murphy, México, 29 de abril de 1845, AHSRE, Leg. 40-11-5.

${ }^{17}$ Desp. 2 de Luis de la Rosa a Tomás Murphy, México, 28 de mayo de 1845, AHSRE, Leg. 40-11-5.

${ }^{18}$ Nota de John Schneider a Tomás Murphy, Londres, 21 de julio de 1845 , AHSRE, Leg. 40-11-5. 
el contrato, ${ }^{19}$ quien respondió que no; pero se comprometió a comunicar las dificultades a su gobierno. ${ }^{20}$

Cuando en septiembre de 1845 se conoció en México la impracticabilidad de la conversión, la casa Manning y Mackintosh desechó el convenio y pidió al gobierno que le reembolsara los 500,000 pesos entregados en mayo y junio. El gobierno, necesitado de recursos, solicitó un nuevo arreglo. De hecho, desde el 28 de julio de 1845 las comisiones Primera de Hacienda y Especial de Texas de la Cámara de Diputados habían emitido un dictamen sobre una iniciativa presentada por el ejecutivo desde el 21 , con el propósito de hacerse de un préstamo nacional o extranjero por $15,000,000$ de pesos. El dictamen manifestaba que al agravarse la situación de una guerra contra Estados Unidos, y agotados los recursos de una solución pacífica, estaban amenazados otros departamentos, por lo que el empréstito no era gravoso al contemplarse las nuevas dimensiones del conflicto. ${ }^{21}$

El segundo intento por restablecer el crédito exterior inicia mediante la celebración de un nuevo contrato entre el secretario de Hacienda, Pedro Fernández del Castillo, y Manning y Mackintosh el 29 de septiembre de 1845 . En este convenio la casa contratista incrementó el fondo a 4,200,000 libras y el período de amortización a 84 años, del $1^{\circ}$ de mayo de 1846 a 1930 , fijándose la conversión de los bonos diferidos y debenturas al $40 \%$ de su valor. El gobierno se comprometía a destinar 108,333 pesos mensuales de la renta del tabaco para el

${ }^{19}$ Nota de John Schneider a Tomás Murphy, Londres, 23 de julio de 1845 , AHSRE, Leg. 40-11-5.

${ }^{20}$ Tomás Murphy, Memoria sobre la deuda esterior de la República Mexicana desde su creación hasta fines de 1847, 1848, París, Imp. de Ad. Blondeau; p. 89-90.

${ }^{21}$ Congreso, Dictamen de la Comisión Primera de Hacienda y Especial de Texas de la Cámara de Diputados, sobre la iniciativa de gobierno para contraer un préstamo nacional o estrangero que proporcione un ingreso al erario de 15 millones de pesos en efectivo, México, 28 de julio de 1845 , Imprenta de José M. Lara. 


\section{ALFONSO CARBALLO}

pago de los dividendos y amortizaciones. ${ }^{22}$ Los bonos activos y la capitalización de los intereses atrasados no estaban contemplados. Además, Fernández del Castillo autorizó a Murphy para que removiera todas las dudas y dificultades que se presentaran en la operación; ${ }^{23}$ esto ocasionaría múltiples controversias en la negociación. Por otra parte, el secretario de Relaciones Exteriores informaba a Murphy que los recursos destinados para el pago de bonos activos estaba garantizado de acuerdo a sus estimaciones: las aduanas marítimas y los derechos de exportación de plata en los puertos del Pacífico producían 6,000,000 y 360,000 pesos anuales respectivamente. ${ }^{24}$ Estando el $20 \%$ de las aduanas destinadas para los bonos activos, sus tenedores podrían mantenerse tranquilos.

La conversión nuevamente tropezó por las condiciones que establecía el contrato entre el gobierno y Manning y Mackintosh, pues su artículo $9^{\circ}$ no permitía la entrega de los bonos del nuevo fondo hasta que la conversión no estuviera asegurada. ${ }^{25} \mathrm{~A}$ pesar de la buena voluntad por parte de la administración de Herrera de llevar a efecto el restablecimiento del crédito exterior, la negociación nuevamente fracasó ante la falta de experiencia de parte de las autoridades hacendarias.

Schneider se comunicó con Tomás Murphy el 22 de noviembre de 1845 y le recomendó que antes de realizar la conversión convocase a una reunión con los tenedores para que éstos acordaran todos los puntos. La casa informaba que así era como se habían efectuado los arreglos de deuda externa de otros países. ${ }^{26}$ En México, Herrera acababa

\section{${ }^{22}$ Casasús, op. cit., p. 199-200.}

${ }^{23}$ Desp. 4 de Pedro Fernández del Castillo a Tomás Murphy, México, 29 de septiembre de 1845, AHSRE, Leg. 40-11-5.

${ }^{24}$ Tomás Murphy, Documentos oficiales relativos a la conversión de la deuda mexicana exterior verificada en 1846, 1846, Londres, Imp. de Carlos Wood y Cía., p. 18.

${ }^{25}$ Nota de John Schneider a Tomás Murphy, Londres, 22 de noviembre de 1845, AHSRE, Leg. 40-11-5.

26 м Nurnhv Memoria..., op. cit., p. 90. 
de ser derribado. El nuevo gobierno encabezado por Mariano Paredes no cambió la estrategia para negociar la deuda.

En Londres Murphy comunicó a su gobierno la recomendación de Schneider el $1^{\circ}$ de diciembre de 1845 . En enero de 1846 el ministro de Relaciones Exteriores le comunicó que el presidente había procurado remover las dificultades de la conversión y redactado un nuevo artículo con la casa Manning y Mackintosh donde se aclaraba el artículo $9^{\circ}$, disculpándose por el que era un error de redacción. ${ }^{27}$ Pedía que de inmediato a que los tenedores de bonos diferidos y debenturas aprobaran la conversión, la casa Schneider emitiera los nuevos bonos. ${ }^{28}$

Schneider informó inmediatamente a los tenedores de bonos; ${ }^{29} \sin$ embargo, en esta ocasión el comité de tenedores de bonos incluyó un nuevo punto en la negociación para que al mismo tiempo se arreglara el pago de todos los intereses atrasados desde octubre de 1844, mediante una capitalización. Mientras tanto en México, al conocer Manning y Mackintosh los nuevos obstáculos, optó por no ratificar el convenio el día 20 de febrero y pidió que se le devolviesen los 500,000 pesos que había entregado al gobierno. Sin embargo, nuevamente intentaron otra negociación. ${ }^{30}$

El gobierno no quería deshacerse de 10 s 500,000 pesos que la casa Manning y Mackintosh le había proporcionado, razón por la que las autoridades insistieran en efectuar la conversión. Asimismo, atisbamos que en los dos intentos de conversión anteriormente expuestos, los obstáculos con que tropezaron las negociaciones eran producto de no haber contemplado las demandas de los tenedores de bonos antes de realizar el convenio. Era obvio que para intentar una conversión

${ }^{27}$ Desp. 5 de Parres a Tomás Murphy, México, 17 de enero de 1846, AHSRE, Leg. 40-11-5.

${ }^{28}$ Artículo aclaratorio entre Manning y Mackintosh y el ministro de Hacienda, anexado ibid.

${ }^{29}$ Nota de John Schneider a Tomás Murphy, Londres, 20 de marzo de 1846, AHSRE, Leg. 40-11-5.

${ }^{30}$ Desp. 6 de Parres a Tomás Murphy, México, 27 de febrero de 1846, AHSRE, Leg. 40-11-5. 


\section{ALFONSO CARBALLO}

de la deuda, deberían de tratarse todos los asuntos pendientes con sus tenedores, especialmente el pago de los intereses atrasados.

El tercer intento comienza cuando el secretario de Hacienda, Luis Parres, firmó un nuevo convenio con Manning y Mackintosh. El decreto de 5 de marzo de 1846 contemplaba que se ampliara el fondo nacional consolidado a 4,650,000 libras con el propósito de cambiar los bonos diferidos y debenturas al $40 \%$ de su valor, a 93 años para amortizar la deuda, pagando 250,000 pesos anuales; los intereses serían del $5 \%$ y contarían a partir del $1^{\circ}$ de junio de 1846; como hipoteca se dejaba la cantidad de 117,708 pesos mensuales de la renta del tabaco y se satisfacía la demanda de capitalizar los intereses atrasados desde octubre de $1844 .{ }^{31}$ Manning y Mackintosh proporcionaría al gobierno $1,600,000$ pesos en efectivo, 1,500,000 pesos en bonos del tabaco, 500,000 pesos de deuda interna del $26 \%, 2,500,000$ pesos en créditos reconocidos que causarían réditos, y 500,000 pesos en créditos reconocidos que no causarían réditos.

En esta nueva operación observamos que Manning y Mackintosh introdujo la entrega de bonos del tabaco al gobierno. La casa financiera planeaba efectuar dicha operación desde 1845, pero ésta se había demorado al enfrentarse un conflicto de intereses con la casa Martínez del Río Hermanos, que también estaba interesada en especular con bonos del tabaco. En el pasado, el gobierno había expedido bonos del tabaco, pues al disolverse la compañía había quedado debiendo dinero a empresarios de este ramo, como Manuel Escandón, Cayetano Rubio, Benito de Maqua, Juan Antonio Béistegui y Muriel Hermanos. ${ }^{32}$ La especulación consistía en que ambas casas habían comprado cierta cantidad de dichos bonos a un precio muy bajo y esperaban que el gobierno se los pagara a un precio mayor. Manning y Mackintosh

${ }^{31}$ Acuerdo del Excmo. Sr. presidente de la República, del 5 de marzo de 1846, apud, Congreso, Leyes..., op. cit., p. XXXVIII-XL.

${ }^{32}$ Rosa María Meyer, "Los ingleses en México, la casa Manning y Mackintosh (1824-1852)", Historias, n 16, enero-marzo de 1987, México, INAH, p. 57-71. 
junto con Escandón se impusieron en el negocio sobre los Martínez del Río y el resto de los empresarios, e hicieron que 1,500,000 pesos en bonos del tabaco fueran reconocidos por el gobierno y aceptados como pago de la casa financiera al gobierno por la creación del fondo nacional consolidado.

El ministro de Hacienda, por instrucciones del presidente, informó a Murphy que quedaba autorizado para remover cualquier dificultad de la negociación; ${ }^{33}$ mientras que el ministro de Relaciones Exteriores, Castillo Lanzas, informaba que el gobierno sí sería solvente para enfrentar sus compromisos de los bonos activos, aunque éstos no estaban contemplados dentro de la conversión de acuerdo a las estimaciones, pues necesitaba ganarse la confianza de todos los tenedores. Además, la renta del tabaco generaba en ese momento 2,000,000 de pesos, por lo que había probabilidades de que dicha renta se pudiera incrementar a la suma de 4,000,000 pesos. ${ }^{34}$ Castillo Lanzas afirmaba: "ha llegado el tiempo de que el buen nombre y crédito de la nación mexicana se hagan efectivos en las extranjeras, sabiendo del triste y deplorable estado de abatimiento en que hoy se hallan por desgracia". ${ }^{35}$ También solicitaba a Murphy que presionara a las autoridades británicas para que contribuyeran al combate del contrabando marítimo en los puertos mexicanos. ${ }^{36}$ Además, informó que el gobierno había encomendado a Manuel Escandón para que se trasladara de Londres y ayudara a las negociaciones con los tenedores de bonos. ${ }^{37}$

Escandón, importante prestamista del gobierno, llegó el 5 de mayo de 1846 y se puso en contacto con Murphy. Éste se comunicó con

${ }^{33}$ Desp. 7 de Parres a Tomás Murphy, México, 7 de marzo de 1846, AHSRE, Leg. 40-11-5.

${ }^{34}$ Desp. 8 de Castillo Lanzas a Tomás Murphy, México, 7 de marzo de 1846, AHSRE, Leg. 40-11-5.

${ }^{35}$ Ibid.

${ }^{36}$ Desp. 8 de Castillo Lanzas a Tomás Murphy, México, 10 de marzo de 1846, AHSRE, Leg. 40-11-5.

${ }^{37} \mathrm{Ibid}$. 


\section{ALFONSO CARBALLO}

Schneider para informarle de la nueva propuesta del fondo de 4,650,000 libras. La casa financiera respondió al ministro mexicano en Londres que ya había informado a los tenedores de bonos sobre el nuevo convenio del 5 de marzo de $1846 .{ }^{38}$ Además, ante el temor de que la casa Lizardi hubiera vendido los bonos diferidos correspondientes a las 784,350 libras que se había negado a entregar, Murphy encomendó a la casa Schneider para que estimara el monto de los mismos que se encontraban en el mercado. La casa sumó en total una cantidad equivalente a 4,624,000 libras en bonos diferidos, que eran las que correspondían al decreto del 15 de diciembre de 1843. Los bonos clandestinos aún no circulaban.

El 11 de mayo, el Comité de Tenedores convocó a una reunión para próximo 18, la cual se celebraría en The London Tavern. Schneider comunicó a Murphy que los tenedores de bonos le solicitaban que también se contemplara dentro de la reunión convocada la negociación de los bonos activos. ${ }^{39}$ Además, le informaba que había recibido serios cuestionamientos por parte de los tenedores de bonos sobre las cifras estimadas de los ingresos de la nación que había realizado el ministro de Relaciones Exteriores, ya que durante el año 1843, el monopolio de la renta del tabaco había producido tan sólo $1,516,670$ pesos. ${ }^{40} \mathrm{La}$ diarios londinenses se mostraron desde un primer momento en contra de la conversión, por lo que los convocados acudieron con desconfianza a la reunión programada. En la misma, los tenedores de bonos denunciaron que el arreglo no contemplaba una conversión sobre todos los bonos. Argumentaban que al considerar únicamente los bonos diferidos y las debenturas, así como la capitalización de los intereses atrasados, y dejar fuera de la conversión a los bonos activos, no distribuía equita-

${ }^{38}$ Nota de J. Schneider a Murphy, Londres, 7 de mayo de 1846, AHSRE, Leg. 40-11-5.

${ }^{39}$ Nota de Schneider a Murphy, Londres, 13 de mayo de 1846, AHSRE, Leg. 40-11-5.

${ }^{40}$ Nota de Schneider a Murphy, Londres, 11 de mayo de 1846, AHSRE, Leg. 40-11-5. 
tivamente los sacrificios entre todos los tenedores, ya que los bonos activos estaban garantizados por el $20 \%$ de las aduanas de Veracruz y Tampico, así como por los derechos de exportación de plata en los puertos del Pacífico. Los bonos diferidos y las debenturas, así como sus intereses, al ser canjeada su amortización por los nuevos bonos quedaban garantizados por medio de la renta del tabaco. ${ }^{41}$

Ante esta contingencia, al día siguiente se reunieron Tomás Murphy, John Schneider, Manuel Escandón y el vicepresidente del Comité de Bonos Hispanoamericanos, para estudiar la situación por la que se habían estancado las negociaciones en la Junta General y para proponer alguna solución. Observaron que el objetivo de llevar a cabo la conversión de la deuda se había demorado demasiado y que conforme pasara el tiempo y se acercara la fecha en que los bonos diferidos comenzaran a generar intereses, sería más difícil establecer la conversión deseada. Al considerar que era el tercer intento realizado para solucionar el problema de la deuda y que el principal obstáculo que los tenedores demandaron en la junta del 18 de mayo era el de un trato equitativo entre los tenedores de los tres tipos de bonos que existían en el mercado, Tomás Murphy realizó una nueva propuesta de conversión para que se ofreciera al Comité de Tenedores. En esencia, el nuevo arreglo distribuía de manera equitativa el sacrificio para los tenedores de los tres tipos de bonos, por lo que el resultado de dicha operación sería idéntico al que se hubiera obtenido si se apegase al convenio del 5 de marzo de $1846 .{ }^{42}$

La nueva propuesta consistía en crear un fondo de $10,241,650$ pesos que contemplara los intereses atrasados; los bonos activos; diferidos y debenturas. La suma de los activos, al comprarse al $90 \%$, pasaría de $5,591,650$ libras a 5,032,475, mientras que los diferidos y debenturas al $60 \%$ pasarían de $5,123,096$ a 3,073,857 libras. A partir del $1^{\circ}$ de julio de 1846 , se deberían cuatro y medio dividendos correspondientes a 629,059 libras. Con la conversión se acordó que de dichos intereses

${ }^{41}$ Murphy, Memoria..., op. cit., p. 101.

${ }^{42}$ Murphy, Documentos..., op. cit., p. 6-7. 


\section{ALFONSO CARBALLO}

atrasados, un dividendo adeudado se pagaría en efectivo y los restantes tres y medio dividendos que corresponden al monto de 489,269 libras desaparecerían y quedarían satisfechos como recompensa al gobierno por haber efectuado la conversión de bonos activos al $90 \%$. Además, el último dividendo correspondiente al $1^{\circ}$ de abril de 1846 se pagaría el próximo $1^{\circ}$ de julio, por lo que el gobierno ahorraría tres meses de intereses sobre el capital de los bonos activos que saldrían de la circulación. ${ }^{43}$ La casa Manning y Mackintosh obtendría 2,135,307 como remanente del fondo. Los intereses de los nuevos bonos sería de $5 \%$ anual y comenzarían a correr a partir de $1^{\circ}$ de julio de 1846 ; las amortizaciones anuales serían de 500,000 pesos. Para lograr ambos objetivos el gobierno destinaría $117,708.33$ pesos mensuales de la renta del tabaco, el $20 \%$ de las recaudaciones de las aduanas de Veracruz y Tampico y todos los derechos de exportación de plata por los puertos del Pacífico. La deuda externa disminuiría a 10,241,650 libras, tal como lo establecía el decreto del 5 de marzo de 1846.

Así Murphy, de acuerdo con Escandón, Schneider y el representante de los tenedores convocó el 4 de junio a una Junta General, donde la nueva propuesta fue aprobada sin objeciones. Los tenedores de bonos estaban satisfechos por atenderse sus demandas y porque el precio que se pagaría por los bonos diferidos y las debenturas era muy atractivo.

¿Qué tan buena fue la negociación efectuada bajo el plan Murphy? Si la comparamos con las tres propuestas anteriores, las cuales no llegaron a aprobarse, efectivamente el plan Murphy no permitía las mismas ganancias para el gobierno que las otras. Pero aún así, generaba una ganancia de $8,411,825$ pesos (menor que las sumas de $12,615,480$, $11,615,480$ y $8,761,300$ pesos de los tres intentos respectivamente). ${ }^{44}$

${ }^{43}$ Propuesta hecha a los tenedores de bonos, y aceptada por éstos el 4 de junio de 1846, apud, Congreso, Leyes..., op. cit., p. XLIV-XLVI.

${ }^{44}$ Las anteriores cifras se derivan de las siguientes operaciones:

1er. intento: $\$ 5,615,480$ del ahorro por la disminución de deuda [que se obtiene restando $£ 5,123,096$ (monto de los bonos diferidos y debenturas) menos $£ 4,000,000$ (monto del nuevo fondo) tomando como tipo de cambio 
Sin embargo, tanto en el tercer intento como en plan Murphy no se están contemplando los ingresos que el gobierno obtendría mediante dos préstamos que sumaban $3,000,000$ pesos: $2,500,000$ en créditos reconocidos con intereses y 500,000 que no causaban intereses. Para

\section{Ganancias del gobierno}

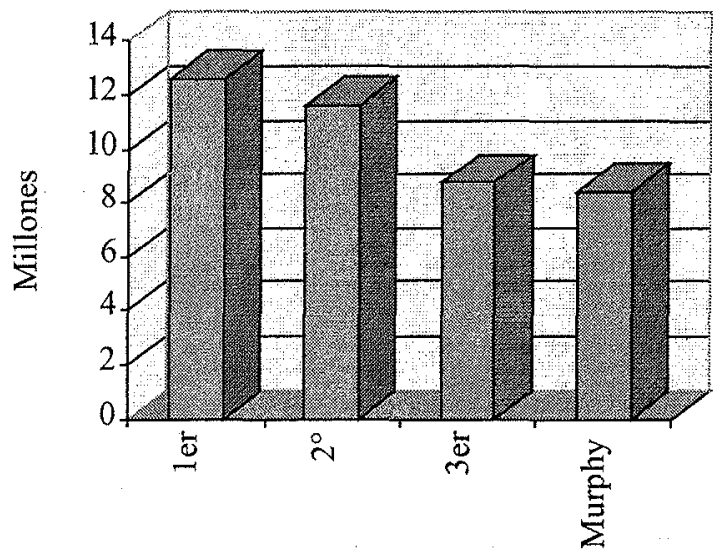

Operación

5 pesos por libra]; más $\$ 5,000,000$ de la deuda interior; más $\$ 2,000,000$ en efectivo que recibió el gobierno hace un total de $\$ 12,615,480$.

2do. intento: $\$ 4,615,480$ de la diferencia de la deuda [restado $£ 5,123,096$ (diferidos y debenturas) menos $£ 4,200,000$ (del nuevo fondo)]; más $\$ 5,000,000$ de deuda interior; más $\$ 2,000,000$ de efectivo hace un total de $\$ 11,615,480$.

3er. intento: $\$ 5,161,300$ de la diferencia de la deuda $[£ 559,164$ de intereses atrasados; más el mismo monto de diferidos y debenturas, $£ 5,123,096]$; $\$ 1,600,000$ en efectivo; $\$ 1,500,000$ en bonos del tabaco; $\$ 500,000$ en bonos de deuda interior hace un total de $\$ 8,761,300$.

Plan Murphy: $\$ 4,811,825$ de la diferencia de la deuda $[£ 11,204,015$ que antes se tenían ( $£ 5,591,650$ de activos; $£ 4,624,000$ de diferidos; $£ 499,096$ de debenturas; $\{489,269$ de intereses que no se cobraron) menos el fondo de $£ 10,241,650]$; más $\$ 1,600,000$ en efectivo; $\$ 1,500,000$ en bonos del tabaco; más $\$ 500,000$ en bonos de deuda interior hace un total de $\$ 8,411,825$. 
ALFONSO CARBALLO

la situación que enfrentaba la nación, el hecho de que se hiciera de tres millones de pesos mediante préstamos, permitía considerar que el plan Murphy en realidad era bueno. Por otra parte ¿por qué los tenedores de bonos aprobaron rápidamente esta propuesta cuando habían desechado las otras? La negociación había sido diseñada bajo el asesoramiento de conocedores del mundo financiero, pero el factor que más persuadió a los tenedores fue que México ya se encontraba en guerra.

En efecto, las noticias de la declaración de guerra llegaron a Londres el 29 de mayo de 1846, seis días antes de la celebración de la Junta General donde se expondría el plan Murphy. Con la guerra, los territorios norteños de México se encontraban amenazados, razón por la cual los tenedores de bonos necesitaban deshacerse de lo establecido por la conversión de 1837 respecto a que los bonos diferidos pudieran canjearse por terrenos baldíos. De hecho, los tenedores habían nombrado una representación ante el gobierno mexicano con el propósito de efectuar la adquisición de terrenos en el Territorio de California; pero nunca obtuvieron respuesta de las autoridades. ${ }^{45}$

El mercado londinense resintió la declaración de guerra, además de los efectos de la crisis financiera, la Potato Famine que azotaba a Irlanda y las malas cosechas de trigo que afectaban a Europa occidental. Los consoles, principal instrumento financiero de deuda británica cayeron de 97 a $96 \frac{1}{2}$ libras, mientras que el papel mexicano tuvo un decremento de $31 \frac{1}{2}$ a $293 / 7 .{ }^{46}$ Una vez firmada la conversión de la deuda mexicana, y al haberse desechado el contrato de conversión de 1837, el precio de sus títulos subieron a $30 \frac{1}{4}$ libras. ${ }^{47}$ Considero que

${ }^{45}$ Guillermo Parish Robertson, Piezas justificadas del arreglo de la deuda esterna de México, que se celebró en 6 de julio de 1849 entre el Excmo. Sr. Ministro de Hacienda Don Francisco de Arrangoiz y Don Guillermo Parish Robertson, comisionado especial de los tenedores de bonos mexicanos en Londres, 1849, México, Tip. de R. Rafael, p. 27.

${ }^{46}$ The Economist, 30 de mayo de 1846, p. 709.

${ }^{47}$ The Economist, 25 de junio de 1846. 
después de la noticia de declaración de guerra, la cotización de los bonos mexicanos no volvieron a ser afectados por los acontecimientos de dicho conflicto armado. En realidad, el desempeño del papel mexicano en Londres fue determinado por las rivalidades políticas en México. Por no ser pertinente un mayor detenimiento en la presente investigación, sólo mencionaré que en 1848 a raíz de la caída de Luis Felipe de Orleáns en Francia, los bonos mexicanos fueron arrastrados por el mercado. ${ }^{48}$

En julio de 1846 unas noticias provenientes vía Nueva York llegaron a Londres anunciando que se preveía la inminente subida al poder de Santa Anna en México. El 22 y 23 de julio el precio de los bonos mexicanos descendieron hasta colocarse a 261/4 libras. El semanario londinense The Economist lo atribuía a la amenaza que sentían los tenedores de bonos ante una administración santannista, pues estaba presente el recuerdo de los grandes fraudes cometidos durante la primera mitad de la década. ${ }^{49}$ Los tenedores de bonos no se equivocaron, con la llegada al poder de Mariano Salas, quien se encontraba bajo la influencia de Santa Anna, el nuevo ministro de Hacienda, Valentín Gómez Farías, el 28 de agosto de 1846 irresponsablemente anuló la conversión de la deuda, ${ }^{50}$ argumentando que Tomás Murphy se había excedido en sus facultades, pues el nuevo convenio se salía del espíritu del decreto de 5 de marzo de 1846. Esgrimía que todos los decretos expedidos para convertir la deuda externa se centraban en

${ }^{48}$ Jan Bazant afirma que en el mes de febrero de 1848 , los tenedores de bonos se vieron desilusionados al conocer los resultados del Tratado de Guadalupe Hidalgo, razón por la que se explica la caída de los precios de los títulos mexicanos; empero, en el semanario londinense The Economist, dicha caída, la cual fue generalizada en la bolsa de Londres, es atribuida a las convulsiones que acontecían en Francia. Jan Bazant, Historia de la deuda exterior de México, 1823-1946, 1995, México, El Colegio de México. The Economist, ejemplares de febrero y marzo de 1848 .

${ }^{49}$ The Economist, 25 de julio de 1846, p. 975.

${ }^{50}$ Desp. 10 de Gómez Farías a Tomás Murphy, México, 28 de agosto de 1846, AHSRE, Leg. 40-11-5. 


\section{ALFONSO CARBALLO}

los bonos diferidos y las debenturas, sin contemplar los bonos activos. Asimismo, que el arreglo gravaba considerablemente los intereses del país al incrementar el fondo nacional de 4,650,000 libras a más de diez millones, conduciendo al gobierno hacia un eventual incumplimiento de sus compromisos. ${ }^{51}$ Además de desconocer la negociación, Gómez Farías responsabilizó a Murphy de las consecuencias que fueran ocasionadas por el convenio y lo destituyó de su cargo. También demandó que dicho desconocimiento de la conversión se publicara en los diarios de Londres para que los tenedores no acudieran a canjear los bonos viejos por los nuevos, informando que las autoridades mexicanas se proponían abrir una nueva negociación. ${ }^{52}$ Gómez Farías pedía que se realizara una reducción del $60 \%$, un incremento del $20 \%$ de los derechos de importación de las aduanas de Veracruz y Tampico, así como de los derechos de exportación de plata por los puertos del Pacífico y los recursos provenientes de la renta del tabaco. Es claro que Gómez Farías anuló el ventajoso plan Murphy por su gran ignorancia en la materia.

La noticia causó el descrédito de la nación en Londres, en momentos en que México se encontraba en plena guerra contra los Estados

46 Unidos. ${ }^{53}$ Los tenedores de bonos acudieron a los abogados de SMB para que sometieran a un dictamen la disposición del gobierno mexicano de desconocer la negociación del 4 de junio de 1846. La respuesta por parte de los abogados consistió en que no había fundamento para que las autoridades mexicanas anularan dicho convenio, pues argumentaban que su ministro plenipotenciario había sido autorizado para remover los obstáculos que se presentaran para llevar a efecto la conversión. ${ }^{54}$

${ }^{51}$ Ibid.

${ }^{52}$ Murphy, Documentos..., op. cit., p. 24-8.

${ }^{53}$ The Economist, 17 de octubre de 1846, p. 361.

${ }^{54}$ Unos Mexicanos, "La conversión de la deuda esterior. Dictamen de los abogados de S.M.B., sobre este importante negocio". Artículo inserto en el $\mathrm{n}^{\circ} 677$ de El Monitor Republicano, México, Imp. de Torres, 31 de octubre de 1846, p. 1-2. 
Tomás Murphy se defendió diciendo que no se había excedido de sus facultades y que el acuerdo firmado el 4 de junio se apegaba al espíritu del decreto del 5 de marzo de 1846. Así lo demostró mediante dos notas enviadas al gobierno el $1^{\circ}$ de junio y el $1^{\circ}$ de julio de 1846 , exhibiendo que los resultados obtenidos se apegaban a las instrucciones giradas por el gobierno. Además mostraba que si se hubiese realizado el acuerdo del 5 de marzo de 1846 al pie de la letra, Manning y Mackintosh hubiese obtenido una ganancia adicional de 46,080 libras en lugar de la obtenida por el convenio del 4 de junio.

Valentín Gómez Farías envió a su hijo Benito a Londres para que junto con la fraudulenta casa Lizardi publicasen la anulación de la conversión. José María Mendoza, cónsul general de México en Londres, a quien se le había encomendado la legación desde el 28 de septiembre de 1846, pidió a Schneider la entrega de bonos, documentos y dinero, dado que había cesado como agente del gobierno en Londres y sería sustituido por Lizardi. Cuando esta noticia llegó a Londres a principios de noviembre el precio de los bonos mexicanos se hundió a $217 / 8 .{ }^{55}$ Schneider se negó a entregar los papeles de la agencia justificándose que cuando se le contrató en 1845 el gobierno se había comprometido a comunicarle su eventual destitución con seis meses de anticipación. Murphy también se negó a entregar la legación a su sucesor. Por lo anterior, Mendoza publicó el 18 de noviembre de 1846 en los diarios londinenses que la casa Schneider ya no sería el agente del gobierno. ${ }^{56}$ Esta noticia causó más descontento entre los tenedores de bonos mexicanos, quienes desconfiaban profundamente de Lizardi.

Mientras tanto en México Gómez Farías llevó a cabo una serie de medidas para que el gobierno se hiciera de fondos. Una de ellas consistió en solicitar dinero a la Iglesia. Ésta argumentó que no tenía efectivo, por lo que Gómez Farías propuso que sus inmuebles sirvieran como garantía de los préstamos que el gobierno solicitara a los

${ }^{55}$ The Economist, 7 de noviembre de 1846, p. 1465.

${ }^{56}$ Murphy, Memoria..., op. cit., p. 123-126. 
comerciantes. El clero se opuso a esta medida y Santa Anna, quien no deseaba romper con tan poderosa institución, ocasionó una crisis ministerial, ${ }^{57}$ removió a Gómez Farías del despacho de Hacienda y puso en su lugar a Antonio Haro y Tamariz, que ya había ocupado la cartera de Hacienda durante los últimos meses de la administración de Santa Anna en 1844, quien tomó posesión el 25 de septiembre. ${ }^{58}$ Al arribar a México de su exilio político, en su paso por Puebla Haro se entrevistó con Benito Gómez Farías quien ya tenía instrucciones de su padre para que publicara en Londres el desconocimiento de la conversión. Haro había manifestado su oposición a la conversión de la deuda exterior, ${ }^{59}$ pero para esas fechas ya se encontraban muy delicadas las finanzas del gobierno mexicano por los gastos de la guerra. El 29 de septiembre de 1846, el ministro de Hacienda informó al encargado de negocios de México en Londres, José María Mendoza, que era imposible que el gobierno cumpliera con los compromisos de la deuda externa, ya que los productos de la renta del tabaco en los Departamentos fronterizos habian disminuido, sus puertos estaban siendo bloqueados, y los fondos provenientes de las aduanas marítimas se destinaban para "urgentes e imperiosas necesidades del pais". 60

Haro reconsideraría las ventajas de la conversión bajo el plan Murphy, decidiendo reconocerla. E1 29 de octubre giró instrucciones para que se pagara el dividendo de enero, justificándose en que la operación ya se encontraba plenamente consumada ${ }^{61}$ La reacción de la opinión pública mexicana en contra de la aprobación no se hizo

${ }^{57}$ Desp. 348 de Salvador Bermúdez de Castro al P.S.D.E., México, 28 de septiembre de 1846, AMAE, Leg. 1649.

${ }^{58}$ Jan Bazant, Antonio Haro y Tamariz y sus aventuras politicas, 18111869, 1985, México, El Colegio de México, p. 47.

${ }^{59} \mathrm{Ibid}$.

${ }^{60}$ Desp. 11 del ministro de Hacienda a José María Mendoza, México, 29 de septiembre de 1846, AHSRE, Leg. 40-11-5.

${ }^{61}$ Desp. 12 de Haro Tamariz a José María Méndoza, México, 29 de octubre de 1846, AHSRE, Leg. 40-11-5. 
esperar, exigiendo que se desecharan las acciones tomadas por Haro, quien finalmente fue removido de su cargo. Como era previsible, el nuevo ministro de Hacienda, José L. Villamil, inmediatamente desconoció la conversión de la deuda y comunicó al encargado de negocios en Londres que no sería sino hasta el 6 de diciembre cuando el Congreso Nacional resolvería sobre la validez de la aprobación. ${ }^{62}$ La versión que en ese momento circulaba entre el público radicaba en que Haro había aprobado la conversión sin haber enterado al presidente de la República, el general Salas, por lo que el ex ministro estuvo a punto de ser enviado a la cárcel. ${ }^{63}$ En junta de ministros, Haro dijo que Salas estaba enterado de las acciones para reconocer la conversión; pero éste lo desmintió. La destitución de Haro era políticamente necesaria para no responsabilizar al presidente. ${ }^{64}$

Para combatir las declaraciones en su contra, el 12 de noviembre Haro publicó un documento donde manifestó su punto de vista. ${ }^{65}$ Afirmaba que si bien en un principio estuvo en contra de la aprobación, cuando analizó detalladamente el mecanismo de la conversión y la situación en que se encontraba el crédito exterior mexicano, se percató de que la operación se hallaba culminada, pues los bonos del nuevo fondo ya estaban circulando por todas las bolsas europeas y resultaba difícil crear un nuevo mecanismo para realizar una nueva conversión, y que en caso de intentarla, la mermada credibilidad del gobierno mexicano por parte de los tenedores imposibilitaría su realización. Haro también diría que encontrándose México en guerra, el honor del país debía mantenerse a toda costa.

Como era de esperarse, los tenedores de bonos mexicanos se enfurecieron cuando conocieron la noticia de desaprobación de la conversión tras la destitución de Haro. La falta de una continuidad política en el problema de la deuda externa hizo que todo se demorara aún

${ }^{62}$ Desp. 12 de Villamil a José María Mendoza, México, 28 de noviembre de 1846, AHSRE, Leg. 40-11-5.

${ }^{63}$ Vid, supra, nota 1.

${ }^{64}$ Bazant, Antonio Haro y Tamariz..., op. cit., p. 51. 


\section{ALFONSO CARBALLO}

más, y con el retraso en la aprobación de la conversión de la deuda, las esperanzas de conseguir nuevos recursos mediante un préstamo extranjero quedarían mermadas.

¿Cuál fue la razón para que las autoridades se negaran a ratificar la conversión de 1846 , a pesar de las ganancias que proporcionaba al gobierno? Murphy la atribuyó en primer lugar a la ignorancia de sus críticos, pero sobre todo a la influencia ejercida por la casa Lizardi. Si la negociación se hubiese llevado a cabo, Lizardi habría estado en una posición muy comprometida debido a la emisión clandestina de los bonos diferidos (recordemos que dicha sobre emisión alcanzaba la considerable suma de 784,350 libras). Además, hay que destacar que Salas y Gómez Farías estaban sentando las bases para que Santa Anna regresara a México de su exilio cubano. Santa Anna apoyaba totalmente a Lizardi, mientras que la administración de Herrera lo hacía a la casa Schneider como agente del gobierno en Londres. ${ }^{66}$

En enero de 1847 el ministro de Relaciones Exteriores informó al nuevo ministro plenipotenciario de México en Londres, José María Luis Mora, que el vicepresidente de México estaba decidido a sostener la reprobación de los convenios o arreglos realizados por Tomás Murphy, argumentando que éste había repasado las instrucciones indicadas por el gobierno mexicano y que el arreglo imponía condiciones excesivas al país. Además de indicar que el anterior ministro de Hacienda, Haro y Tamariz, había actuado sin el acuerdo del jefe del ejecutivo, recomendaba a Mora que era preferible celebrar un nuevo pacto ${ }^{67} \mathrm{Al}$ conocerse la noticia en Londres, los tenedores de bonos emitieron un dictamen donde señalaban que el nuevo ministro de Hacienda mexicano desaprobaba el convenio porque no había entendido sus proce-

${ }^{65}$ Antonio Haro y Tamariz, Estracto del espediente sobre la conversión de la deuda exterior, 1846, México, Imp. de Ignacio Cumplido.

${ }^{66}$ María Teresa Cecilia Autrique Escobar, La misión diplomática de José María Luis Mora (1846-1850), 1989, México, UNAM [Tesis de licenciatura].

${ }^{67}$ Desp. 14 del ministro de Relaciones Exteriores a José María Luis Mora, México, 27 de enero de 1847, AHSRE, Leg. 40-11-5. 
dimientos y ventajas, y acudieron ante el vizconde de Palmerston, secretario del Foreign Office, para que el ministro de Gran Bretaña en México, Charles Bankhead, mediara a su favor poniendo en conocimiento de las autoridades mexicanas dicho dictamen. ${ }^{68}$

Durante el mes de enero de 1847, el presidente del Comité de Bonos Hispanoamericanos, Mr. Robinson, solicitó en varias ocasiones la intervención de Palmerston para que presionara al gobierno mexicano para que reconociera el arreglo llevado a cabo por Murphy. En abril de ese año, Palmerston atendió dichas peticiones y giró instrucciones al ministro de Gran Bretaña en México, Charles Bankhead, para que mediara en favor de los tenedores de bonos. La opinión del gobierno de SMB radicaba en que los tenedores de bonos habían sido tratados injustamente con la desaprobación realizada por las autoridades mexicanas el 18 de noviembre de 1846 que desconocía nuevamente la negociación de la deuda. Las instrucciones de Palmerston consistían en que Bankhead manifestara de manera confidencial al Ministerio de Relaciones Exteriores de México, que el gobierno británico pretendía que las autoridades mexicanas se comprometieran formalmente en que serían respetados los términos del contrato realizado en junio de $1846 .{ }^{69}$ El 18 de mayo de 1847 Charles Bankhead se dirigió al ministro de Relaciones Exteriores, Manuel Baranda, protestando por el decreto de noviembre de $1846 .^{70}$ Ante la presión diplomática efectuada por Gran Bretaña, el 20 de julio de 1847 el gobierno mexicano reconoció la conversión de la deuda externa llevada a cabo por Murphy en $1846 .{ }^{71}$ La ocupación de una parte considerable de México por el

${ }^{68}$ Dictamen del comité de tenedores de bonos hispano-americanos sobre el oficio del Sr. D. Valentín Gómez Farías del 28 de agosto de 1846, apud, Congreso, Leyes..., op. cit., p. XLVII-XLIX.

${ }^{69}$ Minuta [del Foreign Office] a Mr. Bankhead [Londres], 1 de abril de 1847, PRO, F.O. 50/207, ff. 54-46.

${ }^{70}$ Minuta, [del Foreign Office] a Mr. Bankhead [Londres], 3 de julio de 1847, PRO, F.O., 50/207, ff. 89-90.

${ }^{71}$ Desp. de Charles Bankhead a Lord Palmerston, México, 29 de julio de 1847, PRO, F.O., 50/210, ff. 169, 171. 


\section{ALFONSO CARBALLO}

ejército norteamericano no hacía oportuno mantener problemas con una potencia como Gran Bretaña. Santa Anna al ocupar nuevamente la presidencia de México, pese a ser quien más se había opuesto a la aprobación de la conversión por intereses personales con la casa Lizardi, ${ }^{72}$ tuvo que reconocer el arreglo de la deuda y satisfacer las demandas de los tenedores de bonos, diciendo que por consideración a Gran Bretaña y a las gestiones realizadas por Bankhead en defensa de los derechos de los tenedores, acordó junto con los demás ministros de su administración ratificar el arreglo de la conversión realizada en 4 de junio de $1846 .^{73}$ Si bien el cónsul británico en México, Ewen Clark Mackintosh, estaba directamente involucrado en el negocio de la deuda externa, no puedo considerar que sus gestiones fueran las razones principales que motivaron a Palmerston a presionar al gobierno mexicano. En realidad, fueron las quejas de los tenedores de bonos las que determinaron las acciones diplomáticas del secretario de Foreign Office. Un día después del reconocimiento el ministro de Relaciones Exteriores, José Ramón Pacheco, comunicaba a José María Luis Mora, ministro de México en Londres, la resolución de Santa Anna:

Teniendo presentes las manifestaciones que por parte de los interesados en este negocio se han hecho al Supremo Gobierno sosteniendo los derechos que han adquirido a virtud del mencionado arreglo; las gestiones del gobierno de S.M.B., contraidas a... los expresados derechos, las consideraciones debidas a esa potencia amiga, y las razones de conveniencia pública, que si en todo tiempo son dignas de atenderse, deben serlo particularmente en las circunstancias extraordinarias en que se encuentra la nación por la guerra que se hace la de

${ }^{72}$ Desp. 8 de Charles Bankhead a Lord Palmerston, México, 29 de enero de 1847, PRO, F.O., 50/208, ff. 165-167.

73 "Ratificación de la conversión de 1846, hecha por el general Santa Anna", apud, Congreso, Leyes..., op. cit., p. LI. 
los E. Unidos del Norte, he acordado en la junta de Sres. Ministros, y en uso de la facultad que me concede el articulo $1^{\circ}$ de la Ley de 20 de abril último ratificar como por el presente ratifico, la aprobación ya dada al referido arreglo de la conversión de la deuda exterior de la República, [ilegible] por el reducida a la cantidad de $(10,241,650) .^{74}$

El 19 de julio de 1847, un día antes que las autoridades mexicanas ratificaran el arreglo de la deuda externa, la casa Manning y Mackintosh procedió a realizar un nuevo contrato con el ministro de Hacienda, Juan Rondero. Es menester señalar que el artículo primero solicitó enfáticamente - antes que nada - que el ministro de Relaciones Exteriores informara a Bankhead la aprobación del gobierno de la conversión realizada en junio de 1846 . Además, señalaba los puntos en que estaría basado el nuevo contrato, los cuales eran demasiado exigentes para el gobierno, que se encontraba en una situación muy exigida ante los avances en la ocupación de territorio mexicano por tropas estadounidenses. Las modificaciones sobresalientes del nuevo contrato son las siguientes:

La casa Manning y Mackintosh se obligaba ahora a entregar, en calidad de préstamo, 600,000 pesos, de los cuales 400,000 serían pagados en efectivo, reteniendo en su poder a cambio de dicho préstamo la cantidad de 5,000,000 pesos en créditos contra el gobierno. Con lo anterior, se daría plazo hasta el $1^{\circ}$ de abril de 1848 para que el gobierno devolviera los 600,000 pesos prestados, anteriormente señalados. En caso de que no se cumpliera con la devolución en dicha fecha, Manning y Mackintosh se quedaría definitivamente con los créditos de 5,000,000 pesos.

Como ya he señalado, la operación efectuada por Murphy del 4 de junio de 1846 se diferenciaba del contrato del 5 de marzo de ese mismo año, en que resultaba una diferencia en contra de la casa Manning

${ }^{74}$ Desp. 9 del ministro de Relaciones Exteriores a José María Luis Mora, México, 21 de julio de 1847, AHSRE, Leg. 40-11-5. 
y Mackintosh de 45,635 libras, pero el nuevo contrato establecía que dicha diferencia sería reintegrada a la casa financiera.

Por otra parte, el ministro plenipotenciario de México en Gran Bretaña, José María Luis Mora, nombrado por el Congreso General desde el 28 de diciembre de 1846, sería el nuevo encargado de continuar con las operaciones que tuvieran que ver con la deuda externa en Londres. Mora no conocía bien la situación del crédito mexicano, la manera como se habían realizado las negociaciones, ni tampoco el detalle de los fraudes que Lizardi había cometido contra la nación. Mientras tanto Santa Anna después de ratificar el arreglo de la deuda volvería a apoyar a la casa Lizardi. El 27 de julio de ese mismo año expidió una orden dirigida a Mora en donde le instruía a firmar el reconocimiento de las 200,000 libras por concepto de la comisión del $5 \%$ de 1843 que Murphy siempre se negó a reconocer. ${ }^{75}$

Al caer la ciudad de México en poder de las tropas norteamericanas, las autoridades mexicanas se instalaron en Querétaro. Luis de la Rosa, quien se encargó de todos los ministerios existentes en el gobierno provisional, entre ellos el de Hacienda, sabía que se encontraba muy descuidado el asunto de la deuda externa. Le preocupaba que la confu-

54 sión provocada por la guerra propiciara que la casa Lizardi expidiera los bonos diferidos creados de manera clandestina, por lo que recomendaba a Mora que diera seguimiento al caso. ${ }^{76}$ También instaba a Mora a que no firmara los bonos por el monto de 200,000 libras sobre la comisión a Lizardi. Empero las instrucciones de De la Rosa llegaron tarde, pues el ministro en Londres ya había obedecido la orden de Santa Anna.

Con la ocupación de la capital del país por las tropas norteamericanas, muchos archivos del Ministerio de Hacienda se extraviaron, razón por la cual las autoridades mexicanas en Querétaro no contemplaron

\section{${ }^{75}$ Congreso, Leyes..., op. cit., p. L.}

${ }^{76}$ Luis de la Rosa [Comunicación de 12 de marzo de 1848 relativa a la conversión de la deuda exterior], El Eco del Comercio, México, 24 de marzo de 1848, recorte fechado y firmado: Querétaro, 12 de marzo de 1848. 
el vencimiento del plazo sobre el préstamo de 600,000 pesos que Manning y Mackintosh efectuó mediante el nuevo contrato del 19 de julio de 1847. El 29 de febrero - faltando pocas semanas para el vencimiento del contrato - Juan Rondero, quien había sido ministro de Hacienda meses antes, advirtió a De la Rosa que el $1^{\circ}$ de abril de 1848 , para no perder los 5,000,000 de pesos en créditos deberían pagarse 600,000 pesos, como se señalaba en el contrato, pero en ese momento, el gobierno se encontraba sin recursos, por lo que era inminente la pérdida de dicha suma. De la Rosa decidió salvar lo que fuera posible, por lo que el presidente provisional, Manuel de la Peña y Peña, autorizó a que dicho fondo se vendiera a la mejor oferta; es decir, si alguna casa proporcionaba al gobierno una cifra mayor a 600,000 pesos, se haría acreedora de los 5,000,000 de pesos.

Pedro Goyria aceptó la oferta comprometiéndose no sólo a pagar los 600,000 pesos, sino que también pagaría al gobierno la cantidad de 20,000 pesos en efectivo de manera inmediata y 80,000 pesos en cantidades parciales en efectivo a partir del 15 de abril, entregando a la Tesorería General la cantidad de 400,000 pesos en créditos para el $1^{\circ}$ de abril de 1849. Al conocer Manning y Mackintosh la maniobra se negó a recibir la cantidad de 600,000 pesos y a entregar los 5,000,000 pesos en créditos. Ante tal actitud las autoridades declararon nulo el convenio realizado con dicha casa, la cual deseaba aprovecharse de la situación crítica por la que atravesaba la nación. ${ }^{77}$

La firma del Tratado de Guadalupe Hidalgo, por el cual el gobierno estadounidense pagaría al país una cantidad considerable por la venta forzosa de los estados norteños, marcaría el inicio de una nueva conversión de la deuda que culminaría en 1850 , cuando se destinarían a su pago la cantidad de 2,500,000 pesos de los 15,000,000 del monto de la indemnización. ${ }^{78}$ México siguió fuera de los mercados de crédito

${ }_{77}^{7 b i d ., p . ~ 18-21 . ~}$

${ }^{78}$ Existe un breve artículo sobre la relación entre las negociaciones de paz y la deuda exterior mexicana; sin embargo, considero que sus conclusiones no resultan suficientemente esclarecedoras para la dimensión de dicho acontecimiento. Barbara Tennenbaum, "La deuda externa mexicana y el 


\section{ALFONSO CARBALLO}

internacionales y la deuda siguió creciendo. Este hecho limitó las medidas adecuadas para enfrentar la profanación de su suelo por los ejércitos estadounidenses. Sin embargo, como diría Barbara Tennenbaum, a pesar de la inestabilidad, de la insolvencia y de las invasiones, México pudo sobrevivir y finalmente triunfó.

\section{Fuentes y bibliografía}

AMAE, Leg. 1648 y Leg. 1649, Archivo del Ministerio de Asuntos Exteriores de Madrid, (fotocopias).

AHSRE, Leg. 40-11-5, Archivo Histórico de la Secretaría de Relaciones Exteriores.

PRO. F.O. Public Record Office, Londres, Legajos 50/207, 208, 210 (Microfilm depositado en la Biblioteca Daniel Cosío Villegas, El Colegio de México).

Alamán, Lucas, Liquidación general de la deuda esterior de la República Mexicana hasta fin de diciembre de 1841, 1845, México, Imp. Ignacio Cumplido.

Autrique Escobar, María Teresa Cecilia, La misión diplomática de José Maria Luis Mora (1846-1850), 1989, México, UNAM [Tesis de licenciatura]. Bazant, Jan, Antonio Haro y Tamariz y sus aventuras políticas, 18111869, 1985, México, El Colegio de México.

Bazant, Jan, Historia de la deuda exterior de México, 1823-1946, 1995, México, El Colegio de México.

Casasús, Joaquín, Historia de la deuda contraída en Londres, 1885, México, Imp. del Gobierno en Palacio.

Congreso, Leyes, Decretos y Convenios relativos a la deuda extranjera, que se reúnen para la fácil inteligencia del dictamen de la Comisión de Crédito Público de la cámara de diputados, [1850], México, [s.i.].

Congreso, Dictamen de la Comisión de Crédito Público de la Cámara de Diputados, sobre el arreglo de la Deuda Inglesa, 1850, México, Imp. Ignacio Cumplido.

Tratado de Guadalupe Hidalgo", Pasado y presente de la deuda externa de México, 1988, México, Instituto Mora-El Día, p. 43-55. 


\section{LA CONVERSIÓN DE LA DEUDA INGLESA}

Congreso, Dictamen de la Comisión Primera de Hacienda y Especial de Texas de la Cámara de Diputados, sobre la iniciativa de gobierno para contraer un préstamo nacional o estrangero que proporcione un ingreso al erario de 15 millones de pesos en efectivo, México, 28 de julio de 1845, Imprenta de José M. Lara

Congreso, Dictamen de la Primera Comisión de Hacienda de la Cámara de Diputados sobre que se autorice al gobierno arreglar la deuda esterior, México, 22 de abril de 1845.

Haro y Tamariz, Antonio, Estracto del espediente sobre la conversión de la deuda exterior, 1846, México, Imp. de Ignacio Cumplido.

Meyer, Rosa María, "Los ingleses en México, la casa Manning y Mackintosh (1824-1852)", Historias, n 16, enero-marzo de 1827, México, INAH.

Murphy, Tomás, Documentos oficiales relativos a la conversión de la deuda mexicana exterior verificada en 1846, 1846, Londres, Imp. de Carlos Wood y Cía.

Murphy, Tomás, Memoria sobre la deuda esterior de la República Mexicana desde su creación hasta fines de 1847. Por el C. Thomas Murphy, 1848, París, Imp. de Ad. Blondeau.

Parish Robertson, Guillermo, Piezas justificadas del arreglo de la deuda esterna de México, que se celebró en 6 de julio de 1849 entre el Excmo. Sr. Ministro de Hacienda Don Francisco de Arrangoiz y Don Guillermo Parish Robertson, comisionado especial de los tenedores de bonos mexicanos en Londres, 1849, México, Tip. de R. Rafael.

Rodríguez O., Jaime E., "Los primeros empréstitos mexicanos, 18241825", Pasado y presente de la deuda externa de México, 1988, México, Instituto Mora-El Día.

Rosa, Luis de la [Comunicación de 12 de marzo de 1848 relativa a la conversión de la deuda exterior], El Eco del Comercio, México, 24 de marzo de 1848, recorte fechado y firmado: Querétaro, 12 de marzo de 1848.

Tennenbaum, Barbara, "La deuda externa mexicana y el Tratado de Guadalupe Hidalgo", Pasado y presente de la deuda externa de México, 1988, México, Instituto Mora-El Día.

The Economist, años 1846-1848.

Unos Mexicanos, "La conversión de la deuda esterior. Dictamen de los abogados de S.M.B., sobre este importante negocio". Artículo inserto en el $\mathrm{n}^{\circ} 677$ de El Monitor Republicano, México, Imp. de Torres, 31 de octubre de 1846. 